\title{
How consideration of islands has inspired mainstream ecology: links between the theory of island biogeography and some other key theories
}

BH Warren, Muséum National d'Histoire Naturelle, Paris, France

RE Ricklefs, University of Missouri at St. Louis, St. Louis, MO, United States

C Thébaud, Université Paul Sabatier, Toulouse, France

D Gravel, Université de Sherbrooke, Sherbrooke, QC, Canada

N Mouquet, Université de Montpellier, Montpellier, France

Recent years have seen a surge in interest in island biology and the theory of island biogeography (IBT; Losos \& Ricklefs, 2010; Santos et al., 2016; Patino et al., 2017; Whittaker et al., 2017), partly motivated by the $40^{\text {th }}$ and $50^{\text {th }}$ anniversaries of the Core IBT model (MacArthur \& Wilson, 1963) and the monograph that expanded on this model with related ideas (MacArthur \& Wilson, 1967). We were involved in one such initiative, a working group on island biogeography funded by the Centre for the Synthesis and Analysis of Biodiversity (CESAB). A major output of the group was a collective perspective on how key attributes of islands surrounded by water provide prospects for improving our understanding of the ecology and evolution of biological communities in general (Warren et al., 2015; see Box 1 for a detailed distinction of IBT and Core IBT). In the process of organising our ideas, interesting issues arose that were tangential to this aim. One example is that over the decades since 1967, IBT has inspired numerous ecological theories and schools of thought. Although IBT is focussed on islands surrounded by water, even in the opening chapter of the 1967 monograph, MacArthur and Wilson emphasized that such island biomes are an extreme example of fragmented or insular environments (isolated by geography or ecology) that are common worldwide. Consistent with this view, not only has IBT proven relevant to a wide variety of insular environments that are not islands surrounded by water (e.g., Brown, 1971; Drake et al., 2002; Wagner et al., 2014), but it also has links to important ecological theories and concepts, the implications of which stretch far beyond such islands.

Here we highlight some of the main links between IBT and subsequent developments in ecology and conservation biology.

The elegance of Core IBT stands in its ability to model complex phenomena with few 
parameters. Diversity dynamics on an island incorporate a simple birth and death process in which births represent species arriving through immigration and deaths represent local (i.e., island-wide) extinctions; Core IBT predicts that diversity will tend towards a "dynamic equilibrium" in which these processes are balanced. These ideas predict considerable variation in local community composition due to the stochasticity of immigration and local extinction, and the time taken to reach equilibrium (see also Warren et al., 2015, Box 6, for related situations with unattained equilibria). Nonetheless, Core IBT provides a highly deterministic perspective on species richness based on the assumption that the rates of immigration and extinction are determined by the geographic context: near islands have a higher rate of immigration than far islands, and small islands have a higher rate of extinction than large islands. Accordingly, other things being equal, diversity should be highest on islands that are large and close to the mainland, and lowest on islands that are small and far.

The "island biome" (islands surrounded by water) is an obvious choice for studying the effects of area and isolation on species richness since insularity is acute; an island's boundaries frequently provide longstanding limits to the distributions of species or populations (see Warren et al., 2015 for further discussion, including key attributes of islands). Nonetheless, in addition to the predominance of other insular and fragmented environments worldwide, small habitat islands are among those most easily studied and manipulated. Such practical constraints are reflected in the range of systems in which the equilibrium predictions of Core IBT have been tested (Schoener, 2010), which include fragmented crops and intertidal habitats, as well as islands surrounded by water. Application of Core IBT to insular systems that are not "true islands" arguably reached an extreme in the design of protected areas, such as the debate over whether a single large, or several small, reserves is better for ensuring the persistence of species ("SLoSS" for short). Problems with this approach include the fact that Core IBT does not generate clear predictions in this matter (Simberloff \& Abele, 1982), and also that for habitat islands, unlike "true islands", an organism's ability to inhabit, or disperse through, the intervening matrix is a critical factor. In the end, ecologists concluded that Core IBT provides only limited practical lessons for conservation managers (Soulé \& Simberloff, 1986). Nonetheless, by forcing decision makers to think about population turnover within habitat fragments, as well as the influence of fragment size and isolation on colonization and extinction, a highly diversified field of fragmentation research can be traced back to Core IBT (Laurence, 2010). 
A more direct example of the relevance to IBT of insular systems that are not "true islands" comes from an extension to the Core IBT model to improve its ability to predict species diversity. At low isolation, the frequent arrival of propagules protects insular populations from extinction. This "rescue effect" was first demonstrated empirically for arthropods on isolated plants (thistles; Brown \& Kodric-Brown, 1977). Other examples of modifications to Core IBT include adding the effect of island habitat heterogeneity on colonization and extinction dynamics (e.g., Johnson et al., 1968; Whitehead \& Jones, 1969; Kadmon \& Allouche, 2007), as well as the effects of changes in the physical geography of islands over time (Whittaker et al., 2008). Recent developments have extended this legacy by showing how, without adding much complexity to the original model, species interactions could easily be incorporated with important consequences for the shape of the species-area relationship (Gravel et al., 2011) or even for the number of trophic levels expected in fragmented systems (Holt et al., 1999; Calcagno et al., 2011). For example, predator-prey interactions may slow down species accumulation with area, while mutualistic interactions may accelerate it. Realising such multi-trophic extensions to Core IBT was key in the development of recent theories of community assembly and co-distribution in isolated habitats (Cazelles et al., 2015, 2016). Furthermore, some of the main parameters of Core IBT have sometimes been modified to provide new interpretations, as in Wright's (1983) replacing area with available energy to develop a species-energy theory.

Another important extension of IBT was to consider the dynamics of populations on multiple islands (metapopulations) connected by movements of individuals. Although IBT and metapopulation theory (Levins, 1969, 1970) were not formally connected initially, their relationship can be traced back to an agreement among their authors to work on complementary questions, MacArthur and Wilson's being “how many species does an island contain?" and Levins' being "how many islands does a species occupy?" (R. Levins, pers. comm., 2013). This initial plan included the authors coming together later for a study of continental biogeography, although this was never realised (R. Levins, pers. comm., 2013). Current thinking in metapopulation ecology does fit the Core ITB perspective perfectly once changes in scale and geography are incorporated (Hanski, 2010). Core IBT becomes a metapopulation model when one excludes the mainland with its permanent source populations of each species and considers migration among multiple islands (e.g., Mouquet \& Loreau, 2002). Although Levins' $(1969,1970)$ original model focussed on a single species, and "islands" (habitat patches) that did not differ in size or accessibility, numerous later 
developments have relaxed these simplifying assumptions (Hanski, 2001, 2010). Furthermore, it is clear that much heritage of both IBT and metapopulation theory has percolated into today's study of spatial ecology from metacommunities (Leibold et al., 2004; Leibold \& Miller, 2004; Logue et al., 2011; Massol et al., 2011) to metaecosystems (Loreau et al., 2003; Gravel et al., 2011; Massol et al., 2011; Leibold \& Chase, 2017).

Neutral biodiversity theory (Bell, 2001; Hubbell, 2001) is perhaps the most striking example of an unexpected legacy of IBT. MacArthur and Wilson apparently did not intend for IBT to be thought of as "neutral" at the species level (that is, species treated as ecologically equivalent). The concave functional forms for immigration and extinction rates in Core IBT were partially motivated by potential ecological differences between species (differences in propensity for immigration and extinction; MacArthur \& Wilson, 1963; for further discussion see Gilpin and Armstrong 1981; Schoener, 2010). From a strictly technical perspective, however, species in the classic IBT model are not labelled with their ecological identities. Rather, they are all treated as identical, and the model is thus neutral at the species level regardless of the ideas that motivated it.

The better-known form of neutral theory is one in which individuals (not species) are ecologically equivalent (Hubbell, 1979, 1997), and even the earliest work on such models (Caswell, 1976) notes the similarities with IBT. Later development of "The Unified Neutral Theory of Biodiversity and Biogeography" (Hubbell, 2001) caused a wave of interest in neutral models and further added to the legacy of MacArthur and Wilson as an inspiration for them. In particular, the unified neutral theory incorporates an explicit distinction between the local community and metacommunity, with both maintained at dynamic equilibria.

Individual-based neutral theory has since accurately predicted a range of ecological data both in mainstream ecology and in the more specific domain of island biogeography (Bell, 2001; Chave, 2004; Alonso et al. 2006). Although neutral theory is also faced with contrary data (e.g., Ricklefs, 2003, 2006; McGill et al., 2006), it is widely viewed as a useful model to compare with empirical data, highlighting key roles for dispersal limitation, speciation, and ecological drift (Jabot \& Chave, 2011; Rosindell et al., 2011, 2012).

While the influence of IBT in ecology is predominantly linked to Core IBT, it is important to note that the legacy also extends to other elements of the 1967 monograph. For example, Chapter 7 predicts evolutionary changes following island colonization. MacArthur and 
Wilson (1967) reasoned that, upon first arriving on an island, a species' population density is much lower relative to the carrying capacity of the environment than it was at its mainland source. They argued that selection on such newly-arriving immigrants should initially favour adaptations that produce high rates of population growth, even if resources are used inefficiently. They envisaged a contrasting situation for species in the mainland source for which population density is already at the environmental limit; in such source populations, selection should favour the ability to survive and reproduce with limited resources (i.e., efficient resource use). Borrowing notation from standard population models, they coined the terms $r$-selection and $K$-selection for these alternative regimes, respectively. They also argued that once a colonist attains its maximum population size on an island, it will tend to experience a switch back towards a $K$-selection regime (and indeed one that is stronger than on the mainland, due to a temporally more stable climate). MacArthur and Wilson's (1967) ideas were further developed by Pianka (1970) to make explicit predictions for how individual life-history traits would evolve in response to $r$ - and $K$-selection, forming the basis of what became known as life-history strategies. However, the $r$ - and $K$-selection paradigm has since been criticised on numerous grounds, in particular that it has been applied in the absence of data on population dynamics, oversimplifies the process of natural selection, and is unable to make precise predictions about phenotypic change (see Reznick et al. 2002 for a review, and more recent related paradigms). Despite such shortcomings, the $r$ - and $K$ selection paradigm has been useful in defining fitness under density-dependent population regulation (Roff, 1992), and retains considerable popularity (e.g., Saether et al., 2016). Furthermore, consistent with the low species diversity of small and remote islands predicted by Core IBT, such islands provide particularly striking examples of rapid change in selection gradients following the arrival of new immigrants (e.g., Losos et al., 2004, 2006).

IBT is a major component of the foundation of modern ecology. Even though our working group included participants with a range of profiles, including island evolutionary biologists and ecological theoreticians, the number of important links with other ecological theories and schools of thought took many of us by surprise. From an ecological perspective, IBT has left a legacy that has (i) forced ecologists to connect local processes to regional patterns, and (ii) enabled theoretical ecologists to propose simple models that capture a significant portion of ecological complexity on a biogeographic scale. 


\section{References}

Alonso, D., Etienne, R. S., \& McKane, A. J. (2006). The merits of neutral theory. Trends in Ecology \& Evolution, 21, 451-457.

Bell, G. (2001). Neutral macroecology. Science, 293, 2413-2418.

Brown, J. H. (1971). Mammals on mountaintops: nonequilibrium insular biogeography. The American Naturalist, 105(945), 467-478.

Brown, J. H., \& Kodric-Brown, A. (1977). Turnover rates in insular biogeography: effect of immigration and extinction. Ecology, 58, 445-449.

Calcagno, V., Massol, F., Mouquet, N., Jarne, P., \& David, P. (2011). Constraints on food chain length arising from regional metacommunity dynamics. Proceedings of the Royal Society B-

Biological Sciences, 278, 3042-3049.

Caswell, H. (1976). Community structure: a neutral model analysis. Ecological Monographs, 46, 327354.

Cazelles, K., Araujo, M. B., Mouquet, N., \& Gravel, D. (2016). A theory for species co-occurrence in interaction networks. Theoretical Ecology, 9(1), 39-48.

Cazelles, K., Mouquet, N., Mouillot, D., \& Gravel, D. (2015). On the integration of biotic interaction and environmental constraints at the biogeographical scale. Ecography, 39(10), 921-931.

Chave, J. (2004). Neutral theory and community ecology. Ecology Letters, 7, 241-253.

Drake, D. R., Mulder, C. P. H., Towns, D. R., \& Daugherty, C. H. (2002). The biology of insularity: an introduction. Journal of Biogeography, 29, 563-569.

Gilpin, M. E., \& Armstrong, R. A. (1981). On the concavity of island biogeographic rate functions. Theoretical population biology, 20, 209-217.

Gravel, D., Massol, F., Canard, E., Mouillot, D., \& Mouquet, N. (2011). Trophic theory of island biogeography. Ecology Letters, 14, 1010-1016.

Hanski, I. (2001). Metapopulation ecology. Oxford, UK: Oxford University Press.

Hanski, I. (2010). The theories of island biogeography and metapopulation dynamics: science marches forward, but the legacy of good ideas lasts for a long time. In J. B. Losos \& R. E. Ricklefs (Eds.), The theory of island biogeography revisited. Princeton: Princeton University Press.

Holt, R. D., Lawton, J. H., Polis, G., \& Martinez, N. D. (1999). Trophic rank and the species-area relationship. Ecology, 80, 1495-1504.

Hubbell, S. P. (1979). Tree dispersion, abundance, and diversity in a tropical dry forest Science, 203(4387), 1299-1309.

Hubbell, S. P. (1997). A unified theory of biogeography and relative species abundance and its application to tropical rain forests and coral reefs. Coral Reefs, 16, S9-S21. 
Hubbell, S. P. (2001). The unified neutral theory of biodiversity and biogeography. Princeton: Princeton University Press.

Jabot, F., \& Chave, J. (2011). Analyzing tropical forest tree species abundance distributions using a nonneutral model and through Approximate Bayesian Inference. The American Naturalist, 178(2), E37-E47.

Johnson, M. P., Mason, L. G., \& Raven, P. H. (1968). Ecological parameters and plant species diversity. American Naturalist, 102(926), 297-\&. doi:10.1086/282544

Kadmon, R., \& Allouche, O. (2007). Integrating the effects of area, isolation, and habitat heterogeneity on species diversity: A unification of island biogeography and niche theory. American Naturalist, 170, 443-454.

Laurence, W. F. (2010). Beyond island biogeography theory: understanding habitat fragmentation in the real world. In J. B. Losos \& R. E. Ricklefs (Eds.), The Theory of Island Biogeography Revisited. Princeton, NJ: Princeton University Press.

Leibold, M. A., \& Chase, J. M. (2017). Metacommunity Ecology. Princeton, New Jersey: Princeton University Press.

Leibold, M. A., Holyoak, M., Mouquet, N., Amarasekare, P., Chase, J. M., Hoopes, M. F., . . . Gonzalez, A. (2004). The metacommunity concept: a framework for multi-scale community ecology. Ecology Letters, 7(7), 601-613. doi:10.1111/j.1461-0248.2004.00608.x

Leibold, M. A., \& Miller, T. E. (2004). From metapopulations to metacommunities. In I. Hanski \& O. E. Gaggiotti (Eds.), Ecology, Genetics and Evolution of Metapopulations (pp. 133-150). London: Elsevier Academic Press.

Levins, R. (1969). Some demographic and genetic consequences of environmental heterogeneity for biological control. Bulletin of the Entomological Society of America, 15, 237-240.

Levins, R. (1970). Extinction. Lecture Notes in Mathematics, 2, 75-107.

Logue, J. B., Mouquet, N., Hannes, P., Hillebrand, H., \& Group, T. M. W. (2011). Empirical approaches to metacommunities: a review and comparison with theory. Trends in Ecology and Evolution, 26(9), 482-491.

Loreau, M., Mouquet, N., \& Holt, R. (2003). Meta-ecosystem: a framework for a spatial ecosystem ecology. Ecology Letters, 6, 673-679.

Losos, J. B., \& Ricklefs, R. E. (2010). The theory of island biogeography revisited. Princeton, NJ:

Princeton University Press.

Losos, J. B., Schoener, T. W., Langerhans, R. B., \& Spiller, D. A. (2006). Rapid temporal reversal in predator-driven natural selection. Science, 314, 1111.

Losos, J. B., Schoener, T. W., \& Spiller, D. A. (2004). Predator-induced behaviour shifts and natural selection in field- experimental lizard populations. Nature, 505-508.

MacArthur, R. H., \& Wilson, E. O. (1963). An equilibrium theory of insular zoogeography. Evolution, 17, 373-387. 
MacArthur, R. H., \& Wilson, E. O. (1967). The theory of island biogeography. Princeton: Princeton University Press.

Massol, F., Gravel, D., Mouquet, N., Cadotte, M., Fukami, T., \& Leibold, M. (2011). Linking community and ecosystem dynamics through spatial ecology. Ecology Letters, 14, 313-323.

McGill, B. J., Maurer, B. A., \& Weiser, M. D. (2006). Empirical evaluation of neutral theory. Ecology, 87(6), 1411-1423.

Mouquet, N., \& Loreau, M. (2002). Coexistence in metacommunities: the regional similarity hypothesis. The American Naturalist, 159(4), 420-426.

Patino, J., Whittaker, R. J., Borges, P. A. V., Fernandez-Palacios, J. M., Ah-Peng, C., Araujo, M. B., Avila, S. P., Cardoso, P., Cornuault, J., De Boer, E. J., De Nascimento, L., Gil, A., Gonzalez-Castro, A., Gruner, D. S., Heleno, R., Hortal, J., Illera, J. C., Kaiser-Bunbury, C. N., Matthews, T. J., Papadopoulou, A., Pettorelli, N., Price, J. P., Santos, A. M. C., Steinbauer, M. J., Triantis, K. A., Valente, L., Vargas, P., Weigelt, P., \& Emerson, B. C. (2017). A roadmap for island biology: 50 fundamental questions after 50 years of The Theory of Island Biogeography. Journal of Biogeography, 44(5), 963-983. doi:10.1111/jbi.12986

Pianka, E. R. (1970). On r- and K-selection. The American Naturalist, 104(940), 592-597.

Reznick, D., Bryant, M. J., \& Bashley, F. (2002). r- and K-selection revisited: the role of population regulation in life-history evolution. Ecology, 83(6), 1509-1520.

Ricklefs, R. E. (2003). A comment on Hubbell's zero-sum ecological drift model. Oikos, 100, 185192.

Ricklefs, R. E. (2006). The unified neutral theory of biodiversity: do the numbers add up? Ecology, 87(1424-1431).

Roff, D. A. (1992). The evolution of life histories: theory and analysis. New York: Chapman \& Hall. Rosindell, J., Hubbell, S. P., \& Etienne, R. (2011). The unified neutral theory of biodiversity and biogeography at age ten. . Trends in Ecology and Evolution, 26(7), 340-348.

Rosindell, J., Hubbell, S. P., He, F., Harmon, L. J., \& Etienne, R. (2012). The case for ecological neutral theory. Trends in Ecology and Evolution, 274(4), 203-207.

Saether, B. E., Visser, M. E., Grotan, V., \& Engen, S. (2016). Evidence for r- and K-selection in a wild bird population: a reciprocal link between ecology and evolution. Proceedings of the Royal Society B-Biological Sciences, 283(1829). doi:10.1098/rspb.2015.2411

Santos, A. M. C., Field, R., \& Ricklefs, R. E. (2016). New directions in island biogeography. Global Ecology and Biogeography, 25, 751-768.

Schoener, T. W. (2010). The MacArthur-Wilson Equilibrium Model: a chronicle of what it said and how it was tested. In J. B. Losos \& R. E. Ricklefs (Eds.), The Theory of Island Biogeography Revisited (pp. 52-87). Princeton and Oxford: Princeton University Press.

Simberloff, D., \& Abele, L. G. (1982). Refuge design and island biogeographic theory: effects of fragmentation. The American Naturalist, 120(1), 41-50. 
Soulé, M. E., \& Simberloff, D. (1986). What do genetics and ecology tell us about the design of nature reserves. Biological Conservation, 35, 19-40.

Wagner, C. E., Harmon, L. J., \& Seehausen, O. (2014). Cichlid species-area relationships are shaped by adaptive radiations that scale with area. Ecology Letters, 17, 583-592.

Warren, B. H., Simberloff, D., Ricklefs, R. E., Aguilee, R., Condamine, F. L., Gravel, D., Morlon, H., Mouquet, N., Rosindell, J., Casquet, J., Conti, E., Cornuault, J., Fernandez-Palacios, J. M., Hengl, T., Norder, S. J., Rijsdijk, K. F., Sanmartin, I., Strasberg, D., Triantis, K. A., Valente, L. M., Whittaker, R. J., Gillespie, R. G., Emerson, B. C., \& Thebaud, C. (2015). Islands as model systems in ecology and evolution: prospects fifty years after MacArthur-Wilson. Ecology Letters, 18(2), 200-217.

doi:10.1111/ele. 12398

Whitehead, D. R., \& Jones, C. E. (1969). Small islands and equilibrium theory of insular biogeography. Evolution, 23(1), 171-179. doi:10.2307/2406492

Whittaker, R. J., Fernandez-Palacios, J. M., Matthews, T. J., Borregaard, M. K., \& Triantis, K. A. (2017). Island biogeography: Taking the long view of nature's laboratories. Science, 357(6354), 885-+. doi:10.1126/science.aam8326

Whittaker, R. J., Triantis, K. A., \& Ladle, R. J. (2008). A general dynamic theory of oceanic island biogeography. Journal of Biogeography, 35, 977-994.

Wright, D. H. (1983). Species-energy theory: an extension of species-area theory. Oikos, 41, 496-506. 